\title{
Commentary: Treatment of multivessel coronary artery disease in patients with diabetes: Advocating for the best strategy
}

\author{
Thierry Carrel, MD, ${ }^{\mathrm{a}}$ David Reineke, $\mathrm{MD},{ }^{\mathrm{a}}$ and David P. Taggart, $\mathrm{MD}^{\mathrm{b}}$
}

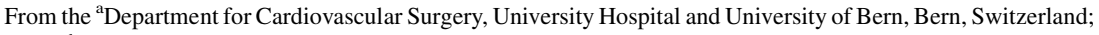 \\ and ${ }^{\mathrm{b}}$ Department of Cardiac Surgery, John Radcliffe Hospital, University of Oxford, Oxford, United Kingdom. \\ Disclosures: Authors have nothing to disclose with regard to commercial support. \\ Received for publication Aug 1, 2019; accepted for publication Aug 1, 2019; available ahead of print Oct 6, 2019 \\ Address for reprints: Thierry Carrel, MD, Department of Cardiovascular Surgery, University Hospital, CH-3010 \\ Bern, Switzerland (E-mail: thierry.carrel@insel.ch). \\ J Thorac Cardiovasc Surg 2020;159:861-4 \\ 0022-5223/\$36.00 \\ Copyright (C) 2019 by The American Association for Thoracic Surgery \\ https://doi.org/10.1016/j.jtcvs.2019.08.016
}

In the paper entitled "The SYNTAX Score According to Diabetic Status: What Does This Mean for the Patient Requiring Myocardial Revascularization?" Ruel and colleagues ${ }^{1}$ advocate that coronary artery bypass grafting (CABG) should be preferentially used over percutaneous coronary intervention (PCI) in any patient with diabetes and multivessel CAD who has a significant survival potential, regardless of the SYNTAX score (ie, even if the SYNTAX score is low or intermediate) or unless there are other contraindications to CABG.

This is a very timely statement in the context of what is already known in the treatment of stable multivessel disease, namely that $\mathrm{CABG}$ is the gold standard in the treatment of complex coronary artery disease (CAD) and the only revascularization treatment with a potential to prolong life. $^{2}$

These considerations are supported by 2 important metaanalyzes that included 111 randomized studies with more than 100,000 patients. In patients with coronary 3-vessel disease, a significant advantage in 5-year survival is observed with CABG compared with PCI. Subgroups analyses confirmed this advantage mainly in patients with diabetes, high complexity of CAD, and in those with reduced left ventricular function. ${ }^{3,4}$

This knowledge has fully been integrated in the most recent guidelines on coronary revascularization from the European Societies of Cardiology and Cardiovascular Surgery. A summary is found in Figure 1. ${ }^{5}$ Although surgical revascularization is recommended as an IA indication for all patterns of 3-vessel coronary disease, PCI is only equivalent for SYNTAX scores $<23$ and only if the patient does not have diabetes. 5

Although the guidelines have produced very clear treatment recommendations in recent years, these are frequently not implemented in clinical practice: This lead, unfortunately, to "nonevidence-based" treatment. The

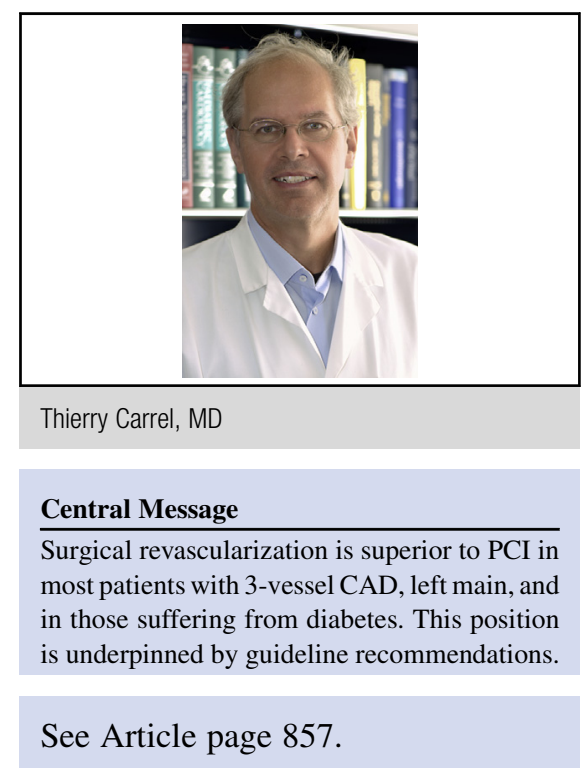

consequences of this have not only been decreasing number of patients scheduled for the most appropriate treatment despite an increasing incidence of the disease itself but also objective disadvantages for the patients, in terms of reduced survival and symptom-free survival and rates of reintervention.

Hannan and colleagues ${ }^{6}$ reported that of 11,000 patients with a clear-cut indication for surgical revascularization, only $50 \%$ actually received CABG. In contrast, when PCI was a possible option, more than $90 \%$ of the patients received PCI. The introduction of drug-eluting stents has markedly boosted this trend. Whereas in $2005,80 \%$ of patients with multivessel disease involving proximal left anterior descending stenosis were treated surgically, by 2015 $43 \%$ received a drug-eluting stent for this pattern of disease $2015 .^{7,8}$

This development did not only influence the actual number of PCI procedures, but Campos and colleagues ${ }^{9}$ reported that implementation of the guidelines may have significant advantages for the patients over the mid-term, with a 5.6\% reduction in mortality, as shown in Figure 2.

Finally, no blame can be attributed to the referring doctors (either the family doctor or the noninvasive cardiologist) if they have been excluded from the treatment allocation process.

Current concerns regarding the referral and treatment process are the result of long-lasting professional and 


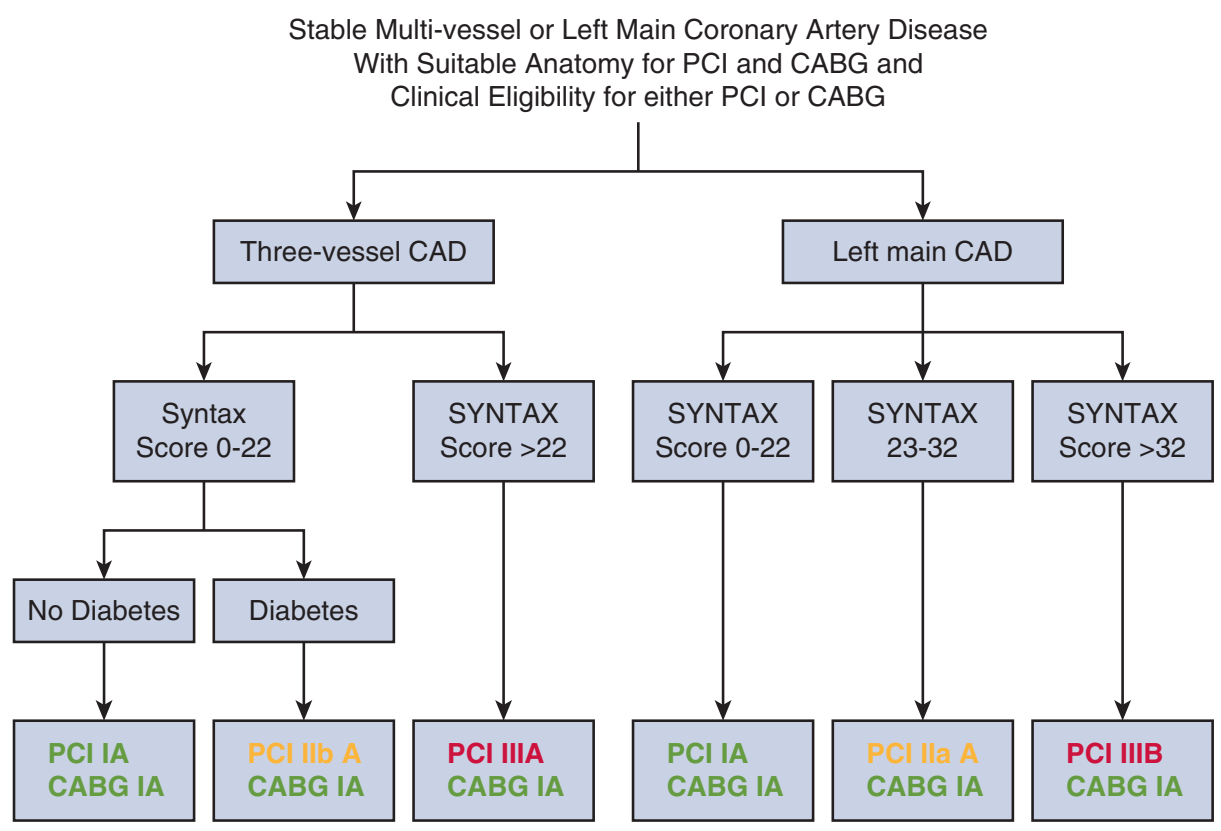

FIGURE 1. Algorithm for the treatment of multivessel coronary artery disease and left main coronary artery according to the most recent guidelines. $P C I$, Percutaneous coronary intervention; $C A B G$, coronary artery bypass grafting, $C A D$, coronary artery disease.

industry-derived biases. This has resulted in 3 important limitations concerning the design of trials of PCI versus CABG over the last 4 decades: (1) the unrepresentative nature of the patient populations; (2) usually short-term follow-up; and (3) occasionally, subsequent adjustment of the study design to fit expectations.
Although daily experience shows that a majority of patients suffering from CAD present with complex multivessel disease and/or left main coronary artery disease and therefore would be best treated with surgical revascularization, study populations, as shown in Figure 3, are usually completely different. A summary of 15 previous

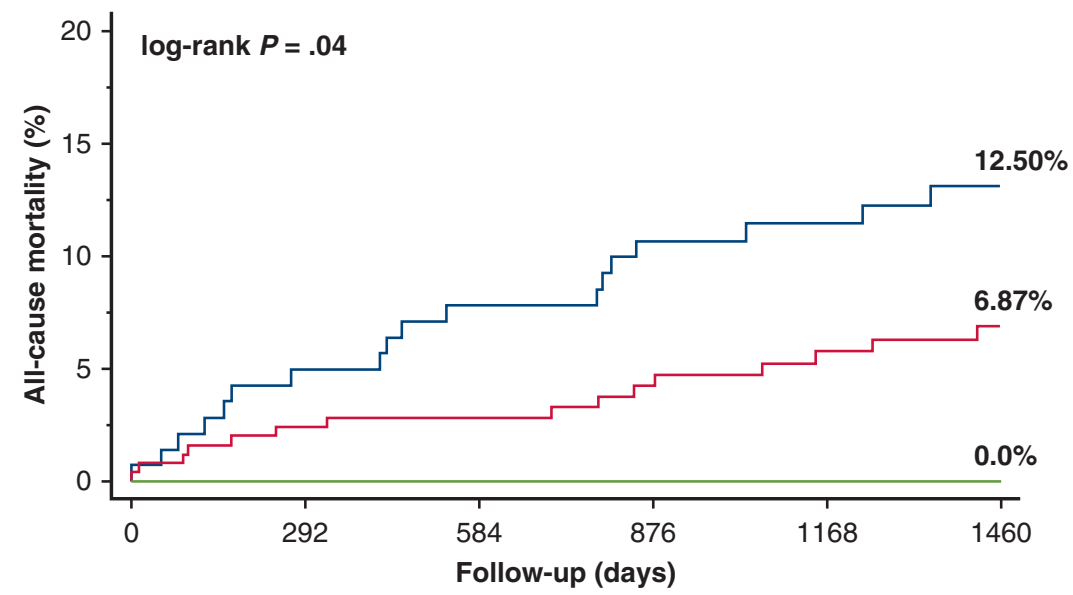

SYNTAX Score II

Treatment Recommendation

\begin{tabular}{lcccccc} 
& CABG & CABG/PCl & PCl & & & \\
\cline { 3 - 3 } & & & & & & \\
Group: $\mathrm{CABG}$ & 142 & 133 & 129 & 123 & 111 & 99 \\
Group: $\mathrm{PCl}$ & 3 & 3 & 3 & 3 & 3 & 2 \\
Group: $\mathrm{CABG} / \mathrm{PCl}$ & 251 & 237 & 226 & 199 & 176 & 156
\end{tabular}

FIGURE 2. Expected survival according to the recommendation (all patients received interventional treatment). $C A B G$, Coronary artery bypass grafting; $P C I$, percutaneous coronary intervention. 


\begin{tabular}{|c|c|c|c|c|c|c|c|c|c|}
\hline Trial & $\mathbf{N}$ & $\begin{array}{l}\text { Pop } \\
\text { (\%) }\end{array}$ & Stent & $\begin{array}{l}\text { LMD } \\
(\%)\end{array}$ & $\begin{array}{l}\text { 3VD } \\
(\%)\end{array}$ & $\begin{array}{l}\text { Proximal } \\
\text { LAD (\%) }\end{array}$ & $E F>.50$ & $\begin{array}{l}\text { DM } \\
(\%)\end{array}$ & $\begin{array}{l}\text { ITA } \\
\text { (\%) }\end{array}$ \\
\hline RITA & 1011 & 4 & - & 0 & 12 & - & - & 6 & 74 \\
\hline ERACI & 127 & 9 & - & 0 & 45 & - & 100 & 11 & 75 \\
\hline LAUSANNE & 134 & 3 & - & 0 & 0 & 100 & - & 12 & 100 \\
\hline GABI & 359 & 4 & - & 0 & 18 & - & - & 10 & 37 \\
\hline EAST & 392 & 4 & - & 0 & 40 & 70 & 100 & 25 & - \\
\hline CABRI & 1054 & 3 & - & 0 & 40 & - & 100 & 12 & 75 \\
\hline MASS & 142 & 69 & - & 0 & - & 100 & 100 & 21 & 100 \\
\hline BARI & 1829 & 12 & - & 0 & 41 & 36 & 100 & 24 & 80 \\
\hline TOULOSE & 152 & 3 & - & 0 & 29 & - & - & 14 & 58 \\
\hline SIMA & 121 & - & $?$ & 0 & - & 100 & 100 & 11 & 100 \\
\hline ERACI II & 450 & 2 & + & 0 & 56 & - & - & 17 & 88 \\
\hline AWESOME & 454 & - & + & 0 & 45 & - & - & - & 70 \\
\hline MASS II & 408 & 2 & + & 0 & 41 & & & & \\
\hline ARTS & 1205 & $5^{a}$ & + & 0 & 32 & - & 100 & 19 & 93 \\
\hline SoS & 988 & $5^{a}$ & + & 0 & 38 & 45 & 100 & 14 & 81 \\
\hline SUMMARY & 8826 & 5 & & 0 & $35 \%$ & 41 & 100 & 16 & 79 \\
\hline CABG (UK) & & & & $>20$ & $>90$ & $>90$ & 30 & 25 & $>90$ \\
\hline
\end{tabular}

${ }^{\mathrm{a}}$ The $5 \%$ is estimated.

FIGURE 3. Summary of relevant studies that were used for the redaction of guidelines. $L M D$, Left main coronary artery disease; $3 V D$, 3-vessel disease; $L A D$, left anterior descending; $E F$, ejection fraction; $D M$, diabetes mellitus; ITA, internal thoracic artery.

randomized studies that significantly influenced the guidelines shows this very clearly; altogether, only $35 \%$ of the patients in the depicted studies had 3-vessel coronary disease, only $40 \%$ had proximal left anterior descending disease, no patients had left main coronary stenosis, and all studies only included patients with a normal left ventricular function.

One of the major advantages of the more recent SYNTAX trial was to include a population far more representative of "real-life" clinical practice, but even so, almost $41 \%$ of the whole population was deemed ineligible for randomization, and the vast majority of these were patients who went straight to CABG because of the anatomical complexity of their disease. ${ }^{10}$

A second limitation is that the large majority of studies have a very short follow-up interval and concluding statements are often reported at 1 year. In view of the long-term issues of coronary artery disease, this is clinically irrelevant in making treatment recommendations. When longer follow-up data are reported, CABG is usually superior to interventional treatment, not only in patients with complex coronary artery morphology but also in those patients in whom PCI had been thought to be equivalent. ${ }^{11}$

Beside the problem of too-short observational intervals, there is another specific study design that may lead to misinterpretation of results. Although surgery has been recognized to be superior to PCI in patients with coronary 3 -vessel disease, left main coronary stenosis has been increasingly treated by PCI, also in patients with a complex morphology. Within this topic, the EXCEL trial ${ }^{12}$ was recently criticized. ${ }^{13}$ Although no statistically differences could be demonstrated in term of combined end points like death, cerebrovascular accidents, and myocardial infarction at 3 years, the biochemical definition of myocardial infarction was changed shortly before assessment of the results that appeared to significantly increase the number of periprocedural incidence of myocardial infarction in the CABG group.

We believe there are 3 major explanations for the durable superiority of CABG over PCI: (1) the specific location of the bypass anastomosis; (2) the completeness of the revascularization; and (3) the expression of vasoactive substances. First, $\mathrm{CABG}$ is performed in the middle-to-distal coronary artery segments. This brings different advantages as compared with PCI: (1) the anastomosis is completely independent of the complexity of the stenotic lesion itself and (2) the bypass has prophylactic qualities, since the segment between the lesion and the site of the more distal anastomosis is protected against additional stenotic lesions. Further, in contrast to stents, bypass grafts enhance development of collaterals. ${ }^{14}$

Second, CABG enhances the possibility of complete revascularization. With regard to this issue, it has been demonstrated in 22,000 patients that survival is related to complete revascularization and in $31 \%$ of these patients this was achieved with arterial revascularization. ${ }^{15}$

Third, the secretion of vasoactive substances from arterial bypass grafts (especially the internal thoracic artery) has to be considered. Endothelial secretion of nitric oxide can increase blood flow through the graft, as well acting 
as stabilizing coronary artery plaque and also as an antithrombotic agent. All these factors may explain the excellent patency rate of $90 \%$ after 20 years observed when the internal thoracic artery has been used. ${ }^{16}$ In contrast, drug-eluting stents inhibit the re-endothelialization process, may act as a prothrombotic, and impair the endothelial function in the more distal coronary artery tree. ${ }^{17}$

The following short conclusions may clarify the mostrecognized indications for patients suffering from coronary artery disease. (1) Surgical revascularization is superior to PCI in most patients with 3-vessel CAD, left main, and in those suffering from diabetes. (2) This position is underpinned by guideline recommendations. (3) Heart teams are the most reliable method to enforce the use of guideline recommendations when they function correctly.

\section{References}

1. Ruel M, Sun LY, Gaudino MF. The SYNTAX score according to diabetic status: what does it mean for the patient requiring myocardial revascularization? J Thorac Cardiovasc Surg. 2020;159:857-60.

2. Taggart D. Coronary artery bypass grafting is still the best treatment for multivessel and left main disease, but the patients need to know. Ann Thorac Surg. 2006; 82:1966-75.

3. Windecker S, Stortecky S, Stefanini G, da Costa BR, Rutjes AW, Di Nisio M, et al. Revascularisation versus medical treatment in patients with stable coronary artery disease: network meta-analysis. BMJ. 2014;348:g3859.

4. Head S, Milojevic M, Daemen J, Ahn J, Boersma E, Christiansen EH, et al. Mortality after coronary artery bypass grafting versus percutaneous coronary intervention with stenting for coronary artery disease: a pooled analysis of individual patient data. Lancet. 2018;391:938-48.

5. Windecker S, Neumann F, Jüni P, Sousa-Uva M, Falk V. Considerations for the choice between coronary artery bypass grafting and percutaneous coronary intervention as revascularization strategies in major categories of patients with stable multivessel coronary artery disease: an accompanying article of the task force of the 2018 ESC/EACTS guidelines on myocardial revascularization. Eur Heart J. 2019;40:204-12.
6. Hannan L, Racz J, Gold J, Cozzens K, Stamato NJ, Powell T, et al. Adherence of catheterization laboratory cardiologists to American College of Cardiology/ American Heart Association guidelines for percutaneous coronary interventions and coronary artery bypass graft surgery: what happens in actual practice? Circulation. 2010;121:267-75.

7. Hannan E, Racz M, Walford G, Jones RH, Ryan TJ, Bennett E, et al. Long-term outcomes of coronary-artery bypass grafting versus stent implantation. $N$ Engl J Med. 2005;352:2174-83.

8. Bangalore A, Guo Y, Samadashvili Z, Blecker S, Xu J, Hannan E. Everolimuseluting stents or bypass surgery for multivessel coronary disease. $N$ Engl J Med. 2015;372:1213-22.

9. Campos C, Stanetic B, Farooq V, Walsh S, Ishibashi Y, Onuma Y, et al. Risk stratification in 3-vessel coronary artery disease: applying the SYNTAX Score II in the Heart Team Discussion of the SYNTAX II trial. Catheter Cardiovasc Interv. 2015;15:E229-38.

10. Head SJ, Holmes DR Jr, Mack MJ, Serruys PW, Mohr FW, Morice MC, et al; SYNTAX Investigators. Risk profile and 3-year outcomes from the SYNTAX percutaneous coronary intervention and coronary artery bypass grafting nested registries. JACC Cardiovasc Interv. 2012;5: 618-25.

11. Stone G, Sabik J, Serruys P, Simonton CA, Généreux P, Puskas J, et al. Everolimus-eluting stents or bypass surgery for left main coronary artery disease. $N \mathrm{Engl}$ J Med. 2016;375:2223-35.

12. Ruel M, Falk V, Farkouh ME, Freemantle N, Gaudino MF, Glineur D, et al. Myocardial revascularization trials. Circulation. 2018;138:2943-51.

13. Doenst T, Haverich A, Serruys P, Bonow RO, Kappetein P, Falk V, et al. PCI and $\mathrm{CABG}$ for treating stable coronary artery disease: JACC review topic of the week. J Am Coll Cardiol. 2019;73:964-76.

14. Hannan EL, Racz M, Holmes DR, King SB III, Walford G, Ambrose JA, et al. Impact of completeness of percutaneous coronary intervention revascularization on long-term outcomes in the stent era. Circulation. 2006;113: 2406-12.

15. Lüscher TF, Diederich D, Siebenmann R, Lehmann K, Stulz P, von Segesser L, et al. Difference between endothelium-dependent relaxation in arterial and in venous coronary bypass grafts. N Engl J Med. 1988;319: 462-7.

16. Reineke DC, Müller-Schweinitzer E, Winkler B, Kunz D, Konerding MA, Grussenmeyer T, et al. Rapamycin impairs endothelial cell function in human internal thoracic arteries. Eur J Med Res. 2015;20:59.

17. Shroyer AL, Hattler B, Wagner TH, Collins JF, Baltz JH, Quin JA, et al. Five-year outcomes after on-pump and off-pump coronary-artery bypass. $N$ Engl J Med. 2017;377:623-32. 